\title{
AS FUNÇÕES SINTÁTICAS ADJUNTO DE NOME E COMPLEMENTO DE NOME NO ENSINO DE LÍNGUA PORTUGUESA: CONTRIBUIÇÕES DA GRAMÁTICA GERATIVA
}

\author{
Mirian Santos de Cerqueira ${ }^{1}$ \\ Leosmar Aparecido da Silva ${ }^{2}$
}

\section{Resumo}

O objetivo do presente artigo é apresentar uma discussão acerca das funções sintáticas adjunto de nome e complemento de nome, confrontando a perspectiva normativa com a perspectiva gerativista dos estudos da linguagem, de modo a contribuir para a reflexão sobre o ensino de Língua Portuguesa na Educação Básica. Do ponto de vista gerativista, partimos de hipóteses acerca da língua-I proposta por Chomsky $(1986,1994)$ no quadro da Teoria de Princípios e Parâmetros, o que nos leva a diferenciar aquisição de aprendizagem. No âmbito das gramáticas normativas, fazemos um breve levantamento, a fim de averiguar possíveis diferenças conceituais entre adjunto de nome (adjunto adnominal) e complemento de nome (complemento nominal). Como metodologia de pesquisa, adotamos o método hipotético-dedutivo. Os resultados de nosso estudo apontam para o fato de que a distinção entre as duas funções sintáticas em questão pode auxiliar os estudantes da Educação Básica do ponto de vista morfossintático, semântico, pragmático e textual-discursivo, razão que nos levou a elaborar uma proposta didática para o ensino dessas funções em aulas de Língua Portuguesa para os níveis fundamental e médio.

Palavras-chave: Adjunto de nome. Complemento de nome. Gramática Gerativa. Educação Básica.

\section{SYNTACTIC FUNCTIONS NOMINAL ADJUNCT AND NOMINAL COMPLEMENT IN THE TEACHING OF PORTUGUESE LANGUAGE: GENERATIVE GRAMMAR'S CONTRIBUTIONS}

\begin{abstract}
In this paper we intend to show a discussion on syntactic functions nominal complement and nominal adjunct, trying to do an opposition between Normative Grammar and Generative Grammar Theory, as soon as possible to contribute to a reflection about Portuguese language classes for Elementary Education. From the generativist framework, we adopt the hypothesis based on I-language, formulated by Chomsky $(1986,1994)$ into the Principle and Parameters Theory, which we take to distinguish the acquisition conception from learning one. Concerning the normative grammars, we do a brief tool to investigate possible conceptual differences between nominal adjunct and complement one. Concerning the research methodology, we

\footnotetext{
${ }^{1}$ Universidade Federal de Goiás - UFG, Goiânia - Goiás, Brasil. Doutora em Linguística pelo Programa de PósGraduação em Letras e Linguística da Universidade Federal de Alagoas. Professora Curso de Licenciatura em Letras: Português e do Curso de Bacharelado em Linguística da Universidade Federal de Goiás, Campus de Goiânia. ORCID <http://orcid.org/0000-0001-5409-3503>. E-mail: mirian_cerqueira@ufg.br.

${ }^{2}$ Universidade Federal de Goiás - UFG, Goiânia - Goiás, Brasil. Doutor em Letras e Linguística pela Universidade Federal de Goiás (UFG). Atua como professor de Linguística e Língua Portuguesa na graduação e na pósgraduação da Faculdade de Letras da Universidade Federal de Goiás. É integrante do Grupo de Estudos Funcionalistas e integra a Rede de estudos de língua portuguesa ao redor do mundo. ORCID $<$ http://orcid.org/0000-0002-3954-3518>. E-mail: silva515@ufg.br.
} 


\section{Linguagens - Revista de Letras, Artes e Comunicação - ISSN 1981- 9943 \\ Blumenau, v. 15, n. 1, p. 074-094, jan./abr. 2021. \\ DOI: http://dx.doi.org/10.7867/1981-9943.2021v15n1p074-094}

adopt the hypothetical-deductive method. The results of our study show that distinction between these two functions can auxiliar students of Elementary Education, through the morphosyntactic, semantic, pragmatic and discourse-textual point of view, that helped us to elaborate a didactic approach for the teaching of these functions in Portuguese Language classes into the Elementary Education.

keywords: Nominal Adjunct. Nominal complement. Generative Grammar. Elementary Education.

\section{INTRODUÇÃO}

Refletir sobre o ensino de Língua Portuguesa na Educação Básica tem sido tarefa realizada por estudiosos da linguagem em diferentes perspectivas teóricas (BRASIL, 1998; NEVES, 2004; VIEIRA; BRANDÃO, 2008, dentre outros). No entanto, quando essa perspectiva é um paradigma formal como o Gerativismo, muito ainda há por ser investigado (AVELAR, 2017; PILATI, 2017; PILATI; NAVES; SALLES, 2019). Pensando nisso, surgiu o nosso interesse em apresentar uma discussão em torno das noções de adjunto de nome e complemento de nome preposicionados (SEDRINS, 2004; 2009; 2016), contrapondo-as ao que é proposto pela Gramática Normativa (BECHARA, 2001).

A escolha por tais noções se justifica pelo fato de esse tema ser considerado um dos mais controversos do ensino de Gramática Normativa na Educação Básica e fora dela. Pensando, então, em como articular as contribuições do Gerativismo ao Ensino de Língua Portuguesa na Educação Básica, nosso artigo seguirá a seguinte sistematização: na Seção 1, fazemos um breve percurso por algumas gramáticas normativas acerca do que elas propõem para as funções sintáticas em questão; na Seção 2, apresentamos a visão da Gramática Gerativa em torno da faculdade da linguagem e seus desdobramentos para a análise das duas funções sintáticas (adjunto de nome e complemento de nome). Na terceira seção, tratamos da metodologia do estudo aqui empreendido. Na quarta seção, elaboramos uma proposta didática para a abordagem das noções de complemento e adjunto de nome voltada para a Educação Básica, uma vez que é nesse nível de ensino que as dúvidas mais se situam, sem, muitas vezes, alcançarem qualquer tipo de explicação mais sistematizada.

\section{O QUE DIZEM AS GRAMÁTICAS NORMATIVAS SOBRE AS FUNÇÕES SINTÁTICAS ADJUNTO DE NOME E COMPLEMENTO DE NOME?}

Comumente, as gramáticas ditas normativo-prescritivas apontam as noções de adjunto de nome e complemento de nome (conhecidas como adjunto adnominal e complemento 


\section{Linguagens - Revista de Letras, Artes e Comunicação - ISSN 1981- 9943 \\ Blumenau, v. 15, n. 1, p. 074-094, jan./abr. 2021. \\ DOI: http://dx.doi.org/10.7867/1981-9943.2021v15n1p074-094}

nominal, respectivamente) como funções sintáticas distintas (BECHARA, 2001). Essa distinção segue uma convenção já estabelecida nas gramáticas latinas, como pode ser verificada na definição proposta por Almeida acerca do termo adjunto adnominal (2001). Para o autor,

\footnotetext{
adjunto adnominal restritivo é o complemento que restringe um nome. Suponhamos a frase 'Casa de Pedro', - A casa podia ser de Paulo, de João, de Antônio etc., mas dizendo 'casa de Pedro' nós restringimos a palavra casa. Portanto, de Pedro, ao mesmo tempo que completa o sentido da palavra casa, está restringindo, está especificando essa palavra. (ALMEIDA, 2001, p. 17).
}

Essa função sintática é conhecida na língua latina como genitivo e está atrelada à ideia de caso morfológico, uma vez que, nesta língua, as funções sintáticas são marcadas por meio de morfemas gramaticais. Para Almeida (2001, p. 17), é importante destacar o fato de que o adjunto adnominal restritivo sempre vem antecedido pela preposição de, encerrando, na maioria dos casos, a ideia de posse. Uma questão que nos chama a atenção na definição de Almeida (2001) é o fato de o autor afirmar ser o adjunto adnominal restritivo um complemento que restringe um nome. Tal afirmação, por si só, já pode contribuir para a dúvida clássica entre os dois termos.

Para Bechara (2001), o adjunto adnominal constitui-se de expansões da expressão nominal que têm a função de "acrescer ideia acidental complementar" ao significado de um substantivo nuclear, tais como noites claras prenunciam bom tempo; o livro está esgotado, esta manhã prometia chuva; belos dias em cidades agradáveis (p. 450).

Há, ainda, segundo Bechara (2001, p. 451), um tipo de adjunto caracterizado por constituir um grupo preposicionado equivalente a um adjetivo, tais como homem de coragem; pão com manteiga; casa de Pedro; cama de solteiro. É justamente este tipo de adjunto que pode provocar dificuldade de distinção do complemento nominal, uma vez que entre eles há muitas semelhanças: a posição à direita do núcleo, a inexistência de pausa, a introdução por preposição.

Bechara (2001, p. 454) considera que os complementos nominais são argumentos selecionados por nomes e atendem às duas condições básicas do estatuto dos argumentos: “a) o núcleo os seleciona semântica e categorialmente; b) o núcleo lhe impõe uma interpretação determinada". Complementos nominais típicos seriam expressos em a remessa dos livros, a resposta ao crítico, a prisão do criminoso. Fato interessante em Bechara (2001) é que em (1) o retrato de Machado de Assis e (2) o retrato da galeria são tratados, respectivamente, como complemento e como adjunto. A justificativa é que em (1) seleciona-se o constituinte argumental Machado de Assis, e o sintagma nominal pode ser reinterpretado como o retrato em 


\section{Linguagens - Revista de Letras, Artes e Comunicação - ISSN 1981- 9943 \\ Blumenau, v. 15, n. 1, p. 074-094, jan./abr. 2021. \\ DOI: http://dx.doi.org/10.7867/1981-9943.2021v15n1p074-094}

que aparece Machado de Assis. Além disso, em (1), utilizando a definição de Almeida (2001), de Machado de Assis está claramente restringindo/especificando um nome. O retrato poderia ser do Paulo, do João etc.

Já, em (2), o adjunto adnominal da galeria corresponde à construção o retrato exposto na galeria. Embora o autor justifique seu posicionamento, tendemos a discordar de que o sintagma preposicional de Machado de Assis seja argumental pelo fato de que a própria sentença reinterpretada (o retrato em que aparece Machado de Assis) constitui uma minissentença com valor adjetival ${ }^{3}$ e, portanto, alinha-se à função de adjunto.

Cunha e Cintra (2007, p. 164-165), assim como Bechara (2001), descrevem as diversas possibilidades de realização do adjunto adnominal: a) adjetivo; b) locução adjetiva; c) artigo (definido ou indefinido); d) pronome adjetivo; e) numeral; e f) oração adjetiva.

Com relação à noção de complemento nominal, os autores propõem o seguinte:

o complemento nominal vem, como dissemos, ligado por preposição ao substantivo, ao adjetivo ou ao advérbio cujo sentido integra ou limita. A palavra que tem o seu sentido completado ou integrado encerra 'uma idéia de relação e o complemento é o objeto desta relação’. (CUNHA; CINTRA, 2007, p. 153).

Para esses autores, tal constituinte pode ser expresso de variadas maneiras, quais sejam: a) substantivo (acompanhado ou não dos seus modificadores); b) pronome; c) numeral; d) palavra ou expressão substantivada; e) oração completiva nominal.

Apesar de apresentar as diversas possibilidades para a expressão do adjunto adnominal e do complemento nominal, gramáticas normativas aqui mencionadas não trazem de maneira precisa as principais diferenças estruturais entre as categorias, o que torna essa tarefa ainda mais difícil tanto para o professor de Língua Portuguesa da Educação Básica quanto para o aluno.

Contestando, pois, o modo como as gramáticas normativas abordam a distinção entre as categorias em análise (complemento nominal e adjunto adnominal), Pinho e Coelho (2019), ancoradas em Ilari (2015), vão propor como critério distintivo entre tais funções a (in)transitividade do substantivo ao qual se liga o termo regido (preposicionado). Para as autoras:

[...] para fins de categorização, torna-se imperioso distinguir entre dois tipos de nomes substantivos: (i) aqueles que exigem um termo preposicionado e (ii) aqueles que o admitem. No primeiro caso, tem-se um nome transitivo e, consequentemente, o termo preposicionado é complemento nominal. No segundo, está-se diante de um nome intransitivo e, portanto, o termo preposicionado é um adjunto adnominal. O que ora

\footnotetext{
${ }^{3}$ A gramática tradicional denomina a sequência [em que aparece Machado de Assis] de oração subordinada adjetiva. Essas orações são introduzidas por pronome relativo e exercem a função de adjunto adnominal do antecedente (o retrato).
} 


\section{Linguagens - Revista de Letras, Artes e Comunicação - ISSN 1981- 9943 \\ Blumenau, v. 15, n. 1, p. 074-094, jan./abr. 2021. \\ DOI: http://dx.doi.org/10.7867/1981-9943.2021v15n1p074-094}

se propõe não constitui, de modo algum, uma regra excêntrica, dado que dialoga intrinsecamente com a noção de subcategorização da sintaxe formal, mas, sem dúvida, parece dar conta de modo mais apropriado dos fatos linguísticos, sem evocar conceitos semânticos para tratar de um fenômeno que é primordialmente sintático (PINHO; COELHO, 2019, p. 207).

A posição das autoras parece dialogar, de alguma maneira, com a perspectiva de análise da Gramática Gerativa, uma vez que considera a seleção ou não de argumentos como questão decisiva para que se (re)pense a distinção argumento/adjunto.

\section{A GRAMÁTICA GERATIVA E AS FUNÇÕES SINTÁTICAS ADJUNTO DE NOME E COMPLEMENTO DE NOME}

Antes de iniciarmos a discussão sobre as categorias adjunto de nome e complemento de nome propriamente ditas, precisamos explicitar o que Chomsky $(1986$; 1994) chama de LínguaI e Língua-E. Essa distinção se faz necessária para compreendermos a dimensão da Sintaxe nos campos de estudo da linguagem. Para Chomsky, a língua-I é o que interessa ao Programa de investigação gerativista, pois é de natureza interna, intensional ${ }^{4}$ e individual, relacionando-se à competência linguística do falante. É no campo da biologia humana que se situa esse conhecimento, ou seja, ele já vem programado no âmbito da mente/cérebro dos falantes, segundo Chomsky. Diferentemente, a língua-E diz respeito à língua como artefato cultural e explicitação da língua-I, ou seja, está relacionada ao desempenho linguístico dos falantes. Para investigar essa questão, o autor irá delimitar seu campo de análise a três questões fundamentais: 1) O que é o conhecimento linguístico? 2) Como esse conhecimento é adquirido? e 3) Como é colocado em uso? Para o presente artigo, interessa-nos, particularmente, as questões 1 e 3 , uma vez que pretendemos distinguir as funções sintáticas do ponto de vista da sua arquitetura gramatical/universal e buscar compreender de que maneira isso pode ser colocado em uso no âmbito do ensino de Língua Portuguesa via Educação Básica.

É importante compreender, também, que a proposta de Chomsky se pauta na ideia de uma Gramática Universal regida por Princípios e Parâmetros. Aqueles são características fundamentais de todas as línguas particulares, ao passo que estes (os parâmetros) são propriedades que distinguem uma língua da outra, devido ao seu caráter variável. Como exemplo do primeiro grupo, temos o fato de que todas as línguas projetam na sintaxe uma posição estrutural para o $\mathrm{DP}^{5}$ sujeito. Como exemplo do segundo grupo, temos a assunção de

\footnotetext{
${ }^{4}$ Intensional pressupõe uma função que combina itens lexicais para formar sintagmas.

${ }^{5}$ Determiner Phrase (Sintagma de Determinante).
} 


\section{Linguagens - Revista de Letras, Artes e Comunicação - ISSN 1981- 9943 \\ Blumenau, v. 15, n. 1, p. 074-094, jan./abr. 2021. \\ DOI: http://dx.doi.org/10.7867/1981-9943.2021v15n1p074-094}

que essa posição pode ou não ser preenchida morfologicamente em algumas línguas. A essa propriedade específica dá-se o nome de Parâmetro do Sujeito Nulo. Línguas que preenchem esse quesito marcam positivamente o valor desse parâmetro, como acontece, por exemplo, em línguas como o Português Europeu e o Italiano. Contrariamente, línguas que não atendem a esse parâmetro marcam-no negativamente, como o Inglês, por exemplo, que é língua de sujeito preenchido.

Dito isso, precisamos apresentar, em primeira instância, o que a Teoria Gerativa convencionou chamar de Sintagma Nominal e suas ramificações, tais como Sintagma de Determinante (cf. ABNEY, 1987). Em seguida, apresentar, brevemente, a Teoria Temática e suas relações com as categorias em estudo (Adjunto de nome e Complemento de nome).

Dentro da perspectiva gerativista, as línguas naturais apresentam em sua sintaxe uma estruturação hierárquica universal de constituintes, conforme pode ser compreendido a partir da ilustração da representação arbórea apresentada em (1):

(1)

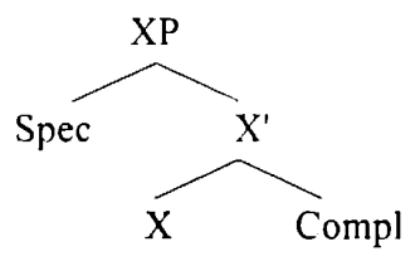

$\mathrm{Na}$ configuração apresentada acima, verificamos o desenho de um sintagma qualquer (XP) valendo tanto para o domínio nominal quanto para o domínio sentencial, quer seja lexical, quer seja funcional. Nessa arquitetura, observamos que as operações se organizam em torno de um núcleo $\mathrm{X}$, o qual também é responsável por hospedar o elemento com as informações mais importantes do sintagma. Vejamos, abaixo, como esse modelo ${ }^{6}$ captura a distinção entre complemento de nome e adjunto de nome:

\footnotetext{
${ }^{6}$ Apesar de reconhecermos a existência de modelos mais recentes e sofisticados para a explicação sintática da distinção entre argumentos e adjuntos no âmbito do Programa Minimalista (cf. SEDRINS, 2009; 2016; AVELAR, 2006) iremos nos limitar, no presente artigo, às assunções propostas dentro da Teoria X-Barra.
} 
Linguagens - Revista de Letras, Artes e Comunicação - ISSN 1981- 9943

Blumenau, v. 15, n. 1, p. 074-094, jan./abr. 2021.

DOI: http://dx.doi.org/10.7867/1981-9943.2021v15n1p074-094

(2)

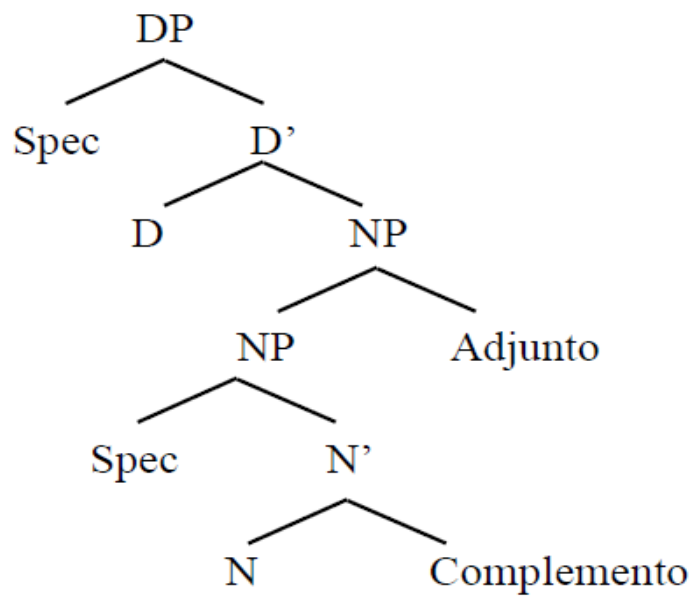

A partir da estruturação hierárquica apresentada, vejamos os exemplos para complemento de nome e adjunto de nome separadamente:

(3) A construção da casa - Complemento de nome

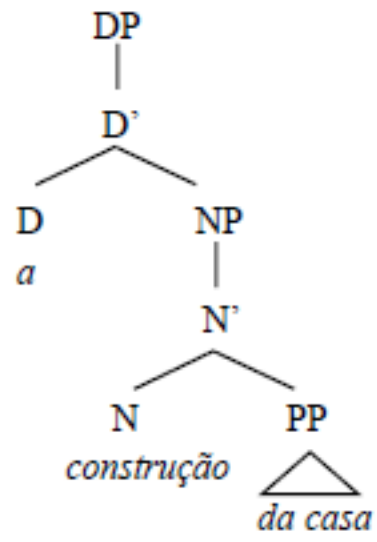

(4) A casa de alvenaria - Adjunto de nome 


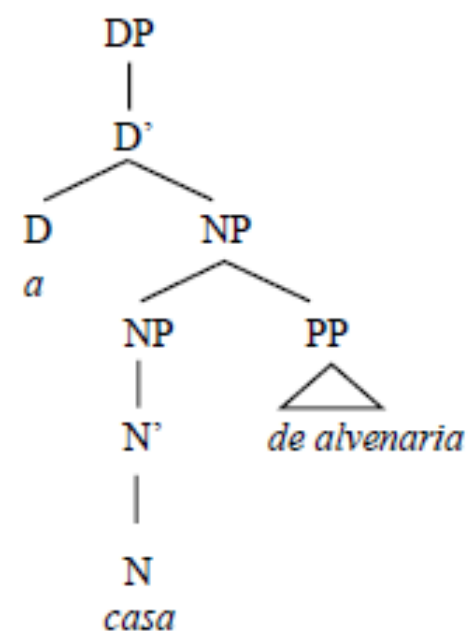

Ao analisar as duas configurações arbóreas apresentadas, precisamos considerar uma diferença central entre tais estruturas: o fato de que complementos, no âmbito da Teoria XBarra, são selecionados categorial e semanticamente (C-seleção e S-seleção) pelo núcleo do sintagma e determinados no léxico, ou seja, são argumentos internos de tais predicados. Contrariamente, adjuntos não são considerados argumentos (internos ou externos) do núcleo, não exercendo, com este, qualquer relação de irmandade (argumento interno) ou especificação (argumento externo). Por isso, sua posição é não-argumental, isto é, não é selecionado pelo núcleo, ligando-se somente ao nível máximo da projeção do núcleo (XP). Diz-se, assim, que argumentos estão incluídos numa determinada estrutura, ao passo que adjuntos estão apenas contidos.

Do ponto de vista da Teoria Temática, é importante apresentarmos algumas breves considerações acerca do seu modo de atuação dentro da perspectiva sintática aqui adotada, a fim de compreendermos os papéis temáticos ${ }^{7}$ (funções semânticas) atribuídos às categorias selecionadas pelos predicados. Segundo Mioto, Silva e Lopes (2013, p. 130),

\begin{abstract}
as informações relativas à s-seleção codificam o que é chamado em teoria gerativa de papel temático ou papel $\theta$ (da letra grega Theta). Estudar como se dá a atribuição dos papéis $\theta$ é tarefa da Teoria $\theta$. É a ela que cabe explicar: quais são os elementos capazes de atribuir papel $\theta$; quais elementos são capazes de receber os papéis $\theta$; qual é o nível sintático em que se dá a atribuição e o recebimento de papéis $\theta$; quais são as posições em que se dá a atribuição e o recebimento de papéis $\theta$; que princípios regulam a atribuição dos papéis $\theta$.
\end{abstract}

Vejamos como essa atribuição de papéis temáticos se dá no âmbito do sintagma $A$ conquista da lua pelo homem, representado na estrutura arbórea seguinte:

\footnotetext{
${ }^{7}$ Por questão de espaço, não abordaremos todos os papéis temáticos possíveis previstos pela Teoria temática. Para maiores informações, consultar Mioto, Silva e Lopes (2013).
} 
(5)

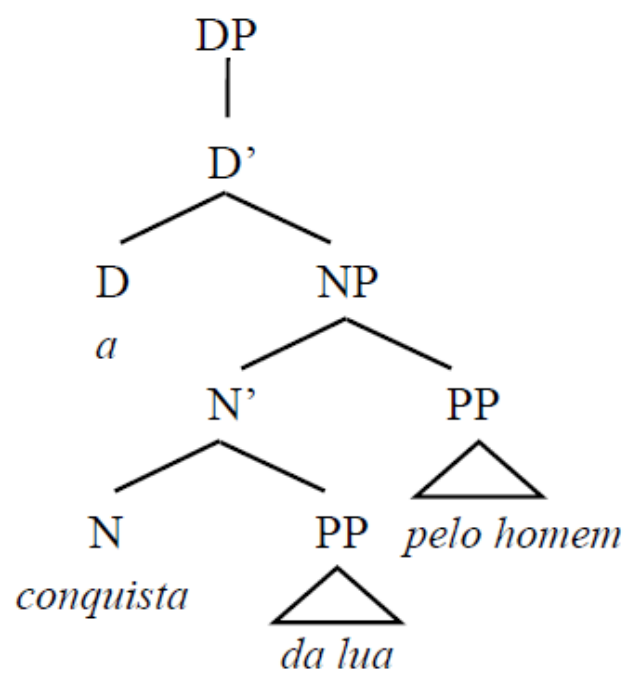

Segundo os autores, o nome deverbal conquista seleciona como argumento interno (complemento) o sintagma preposicional (PP) da lua, e como seu especificador (argumento externo) o sintagma preposicional pelo homem. O papel temático atribuído ao primeiro sintagma é de tema, ao passo que o papel temático atribuído ao segundo é de agente. Ambos os sintagmas preposicionais só estão aptos a receber papel temático porque estão incluídos na projeção máxima do sintagma nominal, ou seja, estão em posição argumental. Do contrário, se fossem adjuntos, não receberiam qualquer papel temático. Tal fato já aponta, de alguma forma, para uma distinção sintático-semântica entre as categorias complemento e adjunto de nome.

É importante destacar, ainda, no âmbito da sintaxe formal de base gerativista, que a noção de complemento está pressuposta na noção mais ampla de argumento, ou seja, o que a Gramática Normativa chama de complemento (verbal ou nominal) é, na verdade, um subtipo da noção mais ampla de argumento, qual seja, argumento interno (em oposição a argumento externo, ou seja, o especificador do núcleo do sintagma). Chama-se interno pelo fato de ser considerado irmão do núcleo (predicado), estabelecendo com este uma relação de irmandade. Essa noção de argumento, por sua vez, é decorrente da lógica de predicados, segundo a qual argumentos preenchem as exigências de seus predicados (NEGRÃO, SCHER; VIOTTI, 2005, p. 97).

Vale destacar, também, que, no âmbito da Teoria X-barra, categorias funcionais intermediárias podem ser vistas na configuração estrutural de um Sintagma de Determinante (DP) cujo núcleo nominal em posição de argumento interno (complemento) seja um nome de natureza deverbal, conforme apontado por Sedrins (2004, p. 24), na estrutura apresentada a seguir: 
(6)

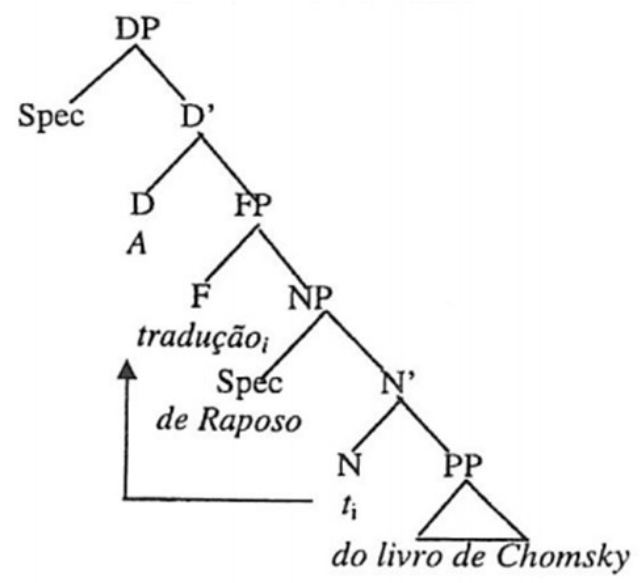

No exemplo apresentado por Sedrins (2004), o nome deverbal [tradução] é deslocado para a posição de núcleo do Sintagma Funcional (FP), para que possa ser interpretado na ordem linear, satisfazendo as interfaces fonética (Forma Fonética) e semântica (Forma Lógica). Na estrutura em questão, a categoria funcional serve, também, para abrigar possíveis sintagmas entre o núcleo de $\mathrm{N}$ e o seu complemento, como em: "o desmatamento desenfreado da mata atlântica pelos civis", em que o adjetivo desenfreado é realizado entre o núcleo nominal desmatamento e o complemento (sintagma preposicional) da mata atlântica.

Em estudo posterior, ao realizar investigação acerca da extração de argumentos e adjuntos de nome em Português, Sedrins (2009) irá optar pelo termo argumento em detrimento do termo complemento. Para o autor:

\footnotetext{
o problema com a dicotomia adjunto/complemento de nome, e que comumente leva a equívocos de análise, é a falta de um termo que possa contemplar construções que não são 'complementos' de um núcleo $\mathrm{X}$, ou seja, não são argumentos internos, como também não são adjuntos, como é o caso dos termos tidos por 'argumentos externos'. (SEDRINS, 2009, p. 58).
}

Dentro dessa perspectiva teórica e agora aplicada ao ensino, Kenedy (2013) defende uma nomenclatura mais enxuta e minimalista para os estudos gramaticais na Educação Básica. Segundo o autor, o estudo da sintaxe deveria partir da noção de sintagma como ponto central de análise e se resumir a quatro categorias fundamentais: sujeito, predicado, argumento e adjunto. Ao tratar especificamente dos termos complemento verbal e nominal, Kenedy chama a atenção para o fato de que nem todos os chamados complementos nominais são, de fato, nucleados por um nome, razão pela qual tal nomenclatura seria inapropriada. Ao invés disso, o autor sugere a oposição complemento verbal versus complemento não-verbal para a categoria dos argumentos internos. 


\section{Linguagens - Revista de Letras, Artes e Comunicação - ISSN 1981- 9943 \\ Blumenau, v. 15, n. 1, p. 074-094, jan./abr. 2021. \\ DOI: http://dx.doi.org/10.7867/1981-9943.2021v15n1p074-094}

Ainda na perspectiva do ensino de Língua Portuguesa, Pilati (2017, p. 101) propõe a noção de aprendizagem ativa, em que o aluno tem papel fundamental em sua aprendizagem, uma vez que um dos pontos de partida é "seu conhecimento linguístico tácito". A autora afirma que é importante que os alunos

realizem tarefas ou enfrentem situações que mobilizem conhecimentos adquiridos, sejam capazes de usar diferentes técnicas e métodos, saibam usar o vocabulário adequado na situação adequada, saibam redigir dentro das normas e construir textos coerentes. (PILATI, 2017, p. 101)

Além disso, uma tarefa fundamental na aprendizagem ativa é a reflexão sobre a língua, ou seja, a colocação em prática da metacognição. Para a autora, a não consideração da reflexão inviabiliza a produção textual, já que é por meio do manejo das estruturas gramaticais que o aluno produtor de textos irá "expressar suas ideias, organizar argumentações, escolher formas de expressar pensamentos.” (PILATI, 2017, p. 93). Daí, compreender o funcionamento da gramática (ordem das palavras, seleção de argumentos, presença de adjuntos, concordância entre os termos na oração, efeitos de sentido decorrentes das diferentes combinações possíveis), para Pilati (2017, p. 106), é de fundamental importância para que o aluno "possa usar de forma consciente os padrões linguísticos de sua língua nas atividades de leitura e produção de textos”.

Considerando, pois, a discussão apresentada pelos autores de base gerativista, concordamos que uma readequação de termos e seu consequente "enxugamento" poderiam ser úteis de algum modo para o processo de ensino gramatical no âmbito da Educação Básica nas escolas brasileiras.

\section{ASPECTOS METODOLÓGICOS}

Quanto à natureza, esta é uma pesquisa aplicada, porque procura transpor didaticamente, na medida do possível, elementos de uma teoria linguística ao ensino de língua portuguesa na escola de nível básico. Quanto à abordagem, é uma pesquisa qualitativa, uma vez que interessam as discussões, problematizações e propostas acerca da temática, e não a quantificação de dados linguísticos. Quanto aos objetivos, é uma pesquisa descritiva, já que se interessa pela descrição das categorias adjunto de nome e do complemento de nome. Quanto aos procedimentos técnicos, caracteriza-se como levantamento, visto que faz um levantamento do tratamento dado aos termos adjunto e do complemento de nome na gramática tradicional, na teoria gerativa, em livro didático e em texto literário. 


\section{Linguagens - Revista de Letras, Artes e Comunicação - ISSN 1981- 9943 \\ Blumenau, v. 15, n. 1, p. 074-094, jan./abr. 2021. \\ DOI: http://dx.doi.org/10.7867/1981-9943.2021v15n1p074-094}

A pesquisa foi motivada pela percepção da dificuldade dos alunos dos cursos de Letras (Licenciatura e/ou bacharelado) e também do ensino básico de identificarem as diferenças sintáticas e semânticas entre as funções adjunto de nome e o complemento de nome.

Considerada essa motivação, a pesquisa dividiu-se, basicamente, em quatro etapas. Num primeiro momento, fez-se um breve levantamento da abordagem do adjunto adnominal e do complemento nominal na gramática normativa, utilizando-se, para isso, da Moderna gramática portuguesa, de Bechara (2001), da Gramática latina, de Almeida (2001) e da Nova gramática do português contemporâneo, de Cunha e Cintra (2007). Num segundo momento, procurou-se descrever, principalmente com base em Sedrins (2004; 2009; 2016) e Kenedy (2013), o tratamento dado pela Gramática Gerativa aos constituintes adjunto adnominal e ao complemento nominal. Num terceiro momento, fez-se uma consulta ao livro didático de Cereja e Magalhães (2008) para verificar como esses autores tratam do tema direcionado para o aluno de Ensino Médio. Num quarto e último momento da pesquisa, procurou-se apresentar uma breve proposta de tratamento do tema do adjunto e do complemento, a partir, principalmente, da análise de um texto literário que explora criativamente a dimensão adjuntiva e argumental do nome.

Apesar de essas quatro etapas não serem exaustivas, procurou-se mostrar a validade da proposta frente às demandas de um ensino significativo tanto para professores quanto para alunos.

\section{ANÁlise E DISCUSSÃO: PROPOSTA DIDÁTICA PARA O ENSINO DAS FUNÇÕES SINTÁTICAS DE ADJUNTO E COMPLEMENTO DE NOME NO ÂMBITO DAS AULAS DE LÍNGUA PORTUGUESA DA EDUCAÇÃO BÁSICA}

Para elaborarmos uma proposta de ensino em torno das funções sintáticas aqui discutidas, tomaremos como pressupostos teóricos a hipótese inatista da linguagem, proposta no âmbito do paradigma gerativista, e a concepção de aprendizagem ativa, delineada por Pilati (2017), tal como já apresentado anteriormente. Na proposta de aprendizagem ativa, a autora enumera três princípios básicos: 1) levar em consideração o conhecimento prévio do aluno; 2) desenvolver o conhecimento profundo dos fenômenos estudados; 3 ) promover a aprendizagem ativa por meio do desenvolvimento de habilidades metacognitivas. Ainda, conforme Pilati (2017, p. 109), na aprendizagem ativa, os alunos não são apenas espectadores, mas são "protagonistas do processo de criação linguística e produção textual, para que possam testar 


\section{Linguagens - Revista de Letras, Artes e Comunicação - ISSN 1981- 9943 \\ Blumenau, v. 15, n. 1, p. 074-094, jan./abr. 2021. \\ DOI: http://dx.doi.org/10.7867/1981-9943.2021v15n1p074-094}

seus conhecimentos, analisar formas gramaticais, reconhecer novas formas e desenvolver suas habilidades linguísticas".

Um aspecto fundamental da aprendizagem ativa é a consideração de que os conhecimentos gramaticais poderão ajudar os alunos a produzir, revisar e analisar textos, fazer leitura crítica, percebendo efeitos de sentido das diferentes escolhas linguísticas.

Pensando nisso e considerando o contexto sócio-histórico de embates políticos no cenário nacional, pode-se iniciar o estudo comparado do adjunto e do complemento de nome, por exemplo, dividindo-se a sala em dois grupos. O primeiro faz uma busca na internet, colocando no buscador, entre aspas, por exemplo, o sintagma nominal crítica ao governo. $\mathrm{O}$ segundo grupo também faz uma busca na internet, inserindo no buscador, também entre aspas, o sintagma nominal crítica do governo. Cada um dos grupos deve escolher uma manchete em que ambos os sintagmas aparecem. Cabe ao professor selecionar duas delas para, juntamente com os alunos, refletir sobre sua constituição sintática e semântica.

A introdução do tema da aula por meio de uma atividade realizada pelos próprios alunos está em conformidade com a proposta de Pilati (2017), segundo a qual o aluno é o protagonista de seu processo de aprendizagem. Alia-se a isso o uso da internet, que, modernamente, está no cotidiano dos alunos.

Uma busca prévia na internet feita para a produção deste texto possibilitou-nos encontrar os seguintes dados:

(7) Crítica ao governo e politica viram temas de fantasias de carnaval ${ }^{8}$

(8) Maia questiona crítica do governo à velha política. ${ }^{9}$

Com base no conhecimento prévio dos alunos, o professor pode iniciar uma análise linguística do cotexto e do contexto comunicativo em que os constituintes sintáticos crítica ao governo e crítica do governo aparecem, perguntando aos alunos a diferença de sentido entre esses dois sintagmas e que elementos linguísticos colaboram para isso.

Possivelmente, os alunos responderão que em (7) o governo é alvo da crítica e em (8) o governo é autor da crítica, e os elementos linguísticos que colaboram para a mudança de sentido são as preposições ao e de. Em termos formais, o sintagma preposicional ao governo constitui

\footnotetext{
8 Disponível em: <https://www.poder360.com.br/brasil/critica-ao-governo-e-politica-viram-temas-de-fantasiasde-carnaval-veja-fotos/ > . Acesso 26 out. 2020.

9 Disponível em: <https://www.metro1.com.br/noticias/politica/72540,maia-questiona-critica-do-governo-avelha-politica-escolher-relator-nao-e-toma-la-da-ca>. Acesso: 26 out. 2020.
} 


\section{Linguagens - Revista de Letras, Artes e Comunicação - ISSN 1981- 9943 \\ Blumenau, v. 15, n. 1, p. 074-094, jan./abr. 2021. \\ DOI: http://dx.doi.org/10.7867/1981-9943.2021v15n1p074-094}

um argumento do nome abstrato crítica, cujo papel temático é o de alvo da crítica; e o sintagma preposicional do governo constitui uma especificação da crítica, que mostra a sua origem.

A diferenciação entre essas duas categorias é importante no ensino básico, porque contribui para a compreensão do fato gramatical e contribui para o desenvolvimento da habilidade metacognitiva, a ponto de o aluno passar a monitorar usos tanto na produção de leitura crítica quanto na produção de textos.

$\mathrm{O}$ professor pode dar continuidade à abordagem do tema adjunto adnominal e complemento nominal, esclarecendo as funções de cada uma das categorias gramaticais. Para isso, pode recorrer a livros didáticos que já fazem a diferenciação funcional das categorias em questão. É o caso de Cereja e Magalhães (2008, p. 310), que esclarecem, em um boxe do livro, que "adjunto adnominal atribui características aos seres e às coisas que nos rodeiam e indica o possuidor, o agente. O complemento nominal é o alvo para o qual se direciona um movimento, um sentimento, uma disposição." Embora a consideração de que o adjunto adnominal indique o agente encontre algum tipo de ressalva entre alguns estudiosos (GUIMARÃES, 2011), por considerarem que não é somente isso que define um adjunto, em algum sentido ela pode ser válida no ensino básico, pelo fato de que não se pode negar que em crítica do governo haja algum tipo de agentividade. Mesmo que o adjunto não projete papéis semânticos, no sintagma como um todo a agentividade aparece. Em outro boxe, os autores esclarecem:

\footnotetext{
Para que serve o adjunto adnominal?

Você já imaginou como seria difícil distinguir a terra seca da terra fértil, o doce de leite do doce de abóbora sem o adjunto adnominal?

Os seres humanos que nos cercam são reconhecidos por suas características: tamanho, peso, matéria, qualidades, defeitos. Quando nos referimos a eles, é o adjunto adnominal o termo sintático responsável pela caracterização e especificação dos nomes (núcleos), independentemente da função sintática que possam desempenhar na oração. (CEREJA; MAGALHÃES, 2008, p. 301).
}

\section{Para que serve o complemento nominal?}

O complemento nominal é utilizado com frequência em textos que lidam com ideias e conceitos abstratos (por exemplo, "direito à liberdade"), quando expressamos nossos desejos, sentimentos e necessidades (por exemplo, “amor à vida") ou quando falamos de nossas ações sobre o mundo empregando nomes derivados de verbos (por exemplo, "transformação da sociedade"). (CEREJA; MAGALHÃES, 2008, p. 307).

Apesar de essa importante distinção estar em um boxe no livro didático e figurar como informação secundária, ela é válida, porque ajuda o aluno a compreender, de forma didática, o que, do ponto de vista semântico e funcional, diferencia o adjunto do complemento. Todavia, apesar de sabermos que há muita controvérsia em torno do que distingue os termos em questão, acreditamos que não seria produtivo o aprofundamento de complexidades gramaticais teóricas, uma vez que o público-alvo - alunos do ensino básico - precisa dessa diferenciação para fins 


\title{
Linguagens - Revista de Letras, Artes e Comunicação - ISSN 1981- 9943 \\ Blumenau, v. 15, n. 1, p. 074-094, jan./abr. 2021. \\ DOI: http://dx.doi.org/10.7867/1981-9943.2021v15n1p074-094
}

práticos relacionados à produção de leitura e de escrita, ou seja, mais no nível linguístico e epilinguístico. Isso, por sua vez, se alinha à consideração de Kenedy (2013) de uma nomenclatura mais enxuta para o ensino de gramática na Educação Básica.

Na sequência, o professor pode trabalhar o texto Congresso internacional do medo, de Carlos Drummond de Andrade. Esse é o ponto central de nossa proposta, visto que, ao trabalhar com um conhecido poema da literatura brasileira, o professor pode integrar ensino de análise linguística e de literatura/interpretação de texto, mostrando em sua prática pedagógica que há diálogo entre as diferentes frentes da língua portuguesa. Não é preciso separar, portanto, a gramática da literatura ou a gramática da interpretação de textos, e nem mesmo da produção textual.

A seguir, reproduzimos, então, o texto de Drummond (ANDRADE, 2012, p. 29):

\section{Congresso Internacional do Medo}

\author{
Provisoriamente não cantaremos o amor, \\ que se refugiou mais abaixo dos subterrâneos. \\ Cantaremos o medo, que esteriliza os abraços, \\ não cantaremos o ódio porque esse não existe, \\ existe apenas o medo, nosso pai e nosso companheiro, \\ o medo grande dos sertões, dos mares, dos desertos, \\ o medo dos soldados, o medo das mães, o medo das igrejas, \\ cantaremos o medo dos ditadores, o medo dos democratas, \\ cantaremos o medo da morte e o medo de depois da morte, \\ depois morreremos de medo \\ e sobre nossos túmulos nascerão flores amarelas e medrosas.
}

Num primeiro momento, recomenda-se que sejam abordadas a leitura, a compreensão e a interpretação desse conhecido texto poético pelos estudantes.

Considerando-se, então, a produção de sentido deste texto, ele trabalha com a temática do medo. Já pelo título, ironicamente, o poeta trata o medo como um sentimento/sensação que aflige todas as pessoas em geral, dada a existência/proposta de um "congresso internacional" desse sentimento.

Conforme Combinato e Crocco (2019), o livro Sentimento do mundo, em que o poema está inserido, foi publicado em 1940, ou seja, no início da Segunda Guerra Mundial. Há, portanto, um vínculo do texto com o contexto histórico-social vivido pelo autor. Isso mostra um dos compromissos da literatura de dialogar com a realidade objetiva tanto no nível da 


\section{Linguagens - Revista de Letras, Artes e Comunicação - ISSN 1981- 9943 \\ Blumenau, v. 15, n. 1, p. 074-094, jan./abr. 2021. \\ DOI: http://dx.doi.org/10.7867/1981-9943.2021v15n1p074-094}

condição humana particular, expressa pelo sentimento do medo; quanto no nível da condição humana universal, expressa pela realidade objetiva da guerra.

Já no início do texto, Drummond coloca em evidência três sentimentos: o amor, o ódio e o medo. Apresenta justificativas para não se $\operatorname{cantar}^{10} \mathrm{o}$ amor, que se refugiou mais abaixo dos subterrâneos; e nem para se cantar o ódio, porque ele não existe. Justifica-se que o momento vivido permite cantar apenas o medo, definido por meio de um aposto como nosso pai e nosso companheiro. Por meio dessa definição poética para o medo, percebe-se que, em relação a nós, ele está numa posição ascendente (nosso pai) e colateral (nosso companheiro).

Na sequência, o poeta, por meio do recurso da enumeração, mostra a existência de um medo generalizado, que se manifesta: 1) em diferentes espaços geográficos ( o medo grande dos sertões, dos mares, dos desertos); 2) em diferentes papéis sociais e institucionais (o medo dos soldados, o medo das mães, o medo das igrejas, [...] o medo dos ditadores, o medo dos democratas); 3) em eventos que expressam o fim da vida (cantaremos o medo da morte); 4) em planos não terrenos ( o medo de depois da morte). Encerra o texto fazendo uma projeção: depois morreremos de medo e sobre nossos túmulos nascerão flores amarelas e medrosas.

Para os objetivos deste texto, interessa-nos sobremaneira a enumeração feita nos versos de 6 a 9, sublinhados no texto, nos quais, o poeta, conhecedor da língua e de suas possibilidades criativas, faz uso ambíguo intencional dos sintagmas nominais. O medo é tão generalizado a ponto de os soldados, as mães, as igrejas provocarem medo nas pessoas ao mesmo tempo em que sentem medo. É tão generalizado que ditadores e democratas também provocam e sentem medo, independentemente de representarem poder e força. A mescla ambígua intencional das noções de origem e alvo para o qual se direciona o medo contribui para categorizar gramaticalmente esses itens lexicais (soldados, mães, ditadores, democratas) tanto como adjuntos adnominais quanto como complementos nominais. Adjunto adnominal, porque a palavra medo admite termo preposicionado à direita, com ideia de posse (o medo pertence aos soldados, às mães, às igrejas, aos ditadores, aos democratas), com função especificativa (pertence à mãe, e não ao filho, por exemplo). Complemento nominal, porque a palavra medo

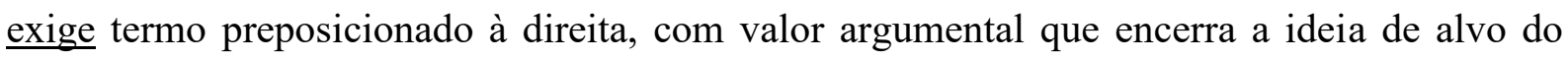
medo.

Se inserirmos outro sintagma preposicional na sentença, a ambiguidade pode ser melhor compreendida:

${ }^{10} \mathrm{O}$ verbo cantar, no texto, é sinônimo de fazer poesia. 


\section{Linguagens - Revista de Letras, Artes e Comunicação - ISSN 1981- 9943 \\ Blumenau, v. 15, n. 1, p. 074-094, jan./abr. 2021. \\ DOI: http://dx.doi.org/10.7867/1981-9943.2021v15n1p074-094}

(9) o medo [da guerra] dos soldados. (a guerra é o elemento causador do medo sofrido pelos soldados)

(10) o medo [dos soldados] das crianças. (os soldados são os causadores do medo sofrido pelas crianças)

As reelaborações em (9) e em (10) mostram que o sintagma preposicional dos soldados tanto pode ser uma especificação do medo (9) quanto o causador do medo (10). Têm, portanto, funções sintáticas diferentes. Em (9), o sintagma preposicional dos soldados funciona como adjunto adnominal e, em (10), dos soldados funciona como complemento nominal. No texto, a omissão da potencial expressão da guerra permite a interpretação de que soldados, mães, ditadores, democratas são, a um só tempo, especificação e causa do medo.

Em sala de aula, o professor, ao analisar o texto com os alunos, pode instigá-los, por meio de perguntas provocadoras, a perceberem a ambiguidade criada por meio de um recurso gramatical com o propósito de se criar o efeito da generalização do medo. Pode, ainda, ajudálos a perceberem que outro recurso utilizado para transmitir a ideia de generalização do medo é a repetição dessa palavra em toda a extensão do texto.

Além dos sentidos permitidos pelo poema, o professor pode ainda testar com os alunos outras possibilidades interpretativas, a partir da movimentação dos constituintes, 'brincando' com a gramaticalidade e com a agramaticalidade desses elementos, ora entendendo partes do sintagma como unidades, ora entendendo-as como independentes. Vejamos:

(11) o medo [Adj.Adn. das mães] [ ${ }^{C N}$ da guerra] [= as mães sentem medo da guerra]

(12) o medo [Adj. Adn. da guerra das mães] [= as mães provocaram uma guerra/a guerra das mães]

Essa movimentação de constituintes, produzindo diferentes efeitos, permite aos alunos compreenderem o que é a ambiguidade intencional e também produzirem suas próprias ambiguidades intencionais na criação de seus textos, assim como fez Drummond.

Quanto aos espaços geográficos - os sertões, os mares, os desertos - haveria maior tendência de se considerá-los causadores do medo (e, portanto, exercendo a função sintática de complemento nominal), pelo fato de, em algum sentido, serem perigosos, especialmente, numa guerra. Numa interpretação metafórica, porém, licenciada pelo texto literário, é possível também compreender tais espaços como possuidores do medo (que sentem o medo). Sertões, 


\section{Linguagens - Revista de Letras, Artes e Comunicação - ISSN 1981- 9943 \\ Blumenau, v. 15, n. 1, p. 074-094, jan./abr. 2021. \\ DOI: http://dx.doi.org/10.7867/1981-9943.2021v15n1p074-094}

mares e desertos, como parte integrante da natureza, sofrem metaforicamente com o medo da destruição, do terror (e, portanto, exercendo a função sintática de adjunto adnominal).

A vantagem da proposta de se trabalhar o adjunto e o complemento por meio da leitura e interpretação do texto de Drummond é a de que os alunos podem ver o funcionamento das categorias gramaticais, produzindo não só a ambiguidade, mas também o efeito da generalização. Além disso, terão a oportunidade de estar em contato com um patrimônio cultural genuinamente brasileiro, em que a língua é instrumento utilizado pelo autor para revelar ao mundo a sua genialidade.

Do ponto de vista do aluno, isso contribui para tornar a gramática do português mais sedutora, instigante e útil, uma vez que o ajuda a ficar mais atento ao ler qualquer gênero textual e também, porque, ao produzir seus próprios textos, conhecendo as diferenças e as semelhanças entre as duas categorias sintáticas, poderá criar, assim como Drummond, seus próprios efeitos de sentido, como já dissemos, e construir uma produção autoral. É exatamente esta a orientação dos documentos oficiais PCN (BRASIL, 1998) e BNCC (BRASIL, 2017): o desenvolvimento das competências linguística, textual e discursiva dos alunos a serviço do desenvolvimento da leitura e da escrita, tal como se pode observar na Figura 1, a seguir:

Figura 1. Desenvolvimento de competências a serviço da leitura e da escrita

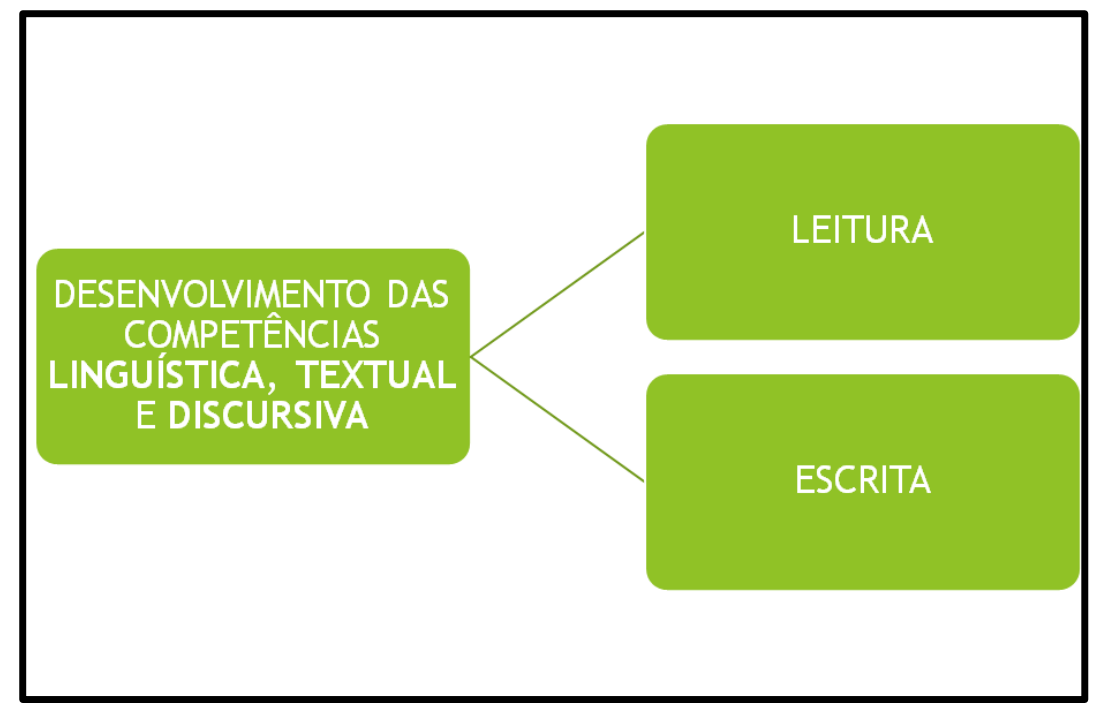

Fonte: os autores

Além do trabalho com o adjunto e com o complemento, o texto oferece inúmeras outras possibilidades de abordagem em sala de aula. Uma delas, por exemplo, é a temática do medo, tanto no âmbito pessoal quanto social. Fica a cargo do professor a continuação do trabalho com o texto, abordando outros aspectos. 


\section{CONSIDERAÇÕES FINAIS}

O presente artigo pretendeu, ainda que de forma breve, abordar a problemática acerca da distinção entre as categorias sintáticas adjunto de nome e complemento de nome, tanto nas perspectivas das gramáticas normativas e da sintaxe formal de cunho gerativista, bem como por meio do tratamento dado pelo livro didático, buscando, na sequência, delinear uma proposta de transposição didática para o ensino de tais categorias na Educação Básica.

A proposta está ancorada nos princípios da aprendizagem ativa (PILATI, 2017) de que se deve levar em consideração o conhecimento prévio e/ou a intuição linguística que o aluno já possui, desenvolver reflexão sobre os fenômenos da língua e colocar o aluno como agente de sua própria aprendizagem. O ponto central da proposta é a análise do texto Congresso Internacional do Medo, de Drummond, no qual o autor usa sintagmas do tipo o medo dos soldados, o medo das mães, o medo das igrejas. Em tais sintagmas, os termos preposicionados podem ser interpretados ambiguamente como uma especificação de quem sente o medo ou uma determinação do causador do medo, refletindo as categorias adjunto e complemento de nome respectivamente. Se se diz, por exemplo, (i) João teme a guerra e (ii) O medo [da guerra] do João, em (i) João é argumento externo de temer e a guerra é seu argumento interno. Da mesma forma, em (ii), da guerra é o argumento interno de medo e, por isso, o complemento nominal e João é o argumento externo de medo e o adjunto adnominal. Percebe-se aí uma estreita relação entre a função sintática sujeito oracional e a função sintática adjunto adnominal. Essa relação pode ser percebida também entre a função sintática objeto e complemento nominal.

A nossa defesa é a de que a percepção desses usos, com a provocação e o auxílio do professor, pode levar o aluno a desenvolver habilidades metacognitivas sobre a língua e, refletindo sobre os fenômenos linguísticos observáveis, o aluno pode utilizá-los criativamente ao produzir seus textos, com a vantagem de entrar em contato com um patrimônio cultural brasileiro de nossa literatura e de estudar integradamente língua e literatura.

\section{REFERÊNCIAS}

ABNEY, S. The English noun phrase and its sentential aspect. $\mathrm{PhD}$ Dissertation. Massachusetts: MIT, 1987.

ALMEIDA, N. M. Gramática latina. 30. ed. atualizada. São Paulo: Saraiva, 2001. 
ANDRADE, Carlos Drummond de. Congresso internacional do medo. In: ANDRADE, Carlos Drummond de. Sentimento do mundo. São Paulo: Companhia das Letras, 2012. p. 29.

AVELAR, J. O. Saberes gramaticais na escola. São Paulo: Pontes, 2017.

AVELAR, J. O. de. Adjuntos adnominais preposicionados no português brasileiro. Tese (Doutorado em Linguística) - Programa de Pós-graduação em Linguística, Universidade Estadual de Campinas. Campinas, 2006.

BECHARA, E. Moderna gramática portuguesa. 37. ed. revista e ampliada. Rio de Janeiro: Lucerna, 2001.

BRASIL. Ministério da Educação. Base Nacional Comum Curricular. Brasília: SEF, 2017.

BRASIL. Ministério da Educação e Desporto. Parâmetros Curriculares Nacionais. $3^{\mathbf{o}}$ e $4^{\mathbf{0}}$ ciclos do ensino fundamental. Brasília: SEF, 1998.

CHOMSKY, N. Knowledge of language, its nature, origin, and use. New York: Praeger, 1986.

CHOMSKY, N. Bare phrase structure. MIT Ocasional Papers in Linguistics 5, 1994.

COMBINATO, D. S.; CROCCO, F. L. T. A literatura empenhada em Antonio Candido: contribuições para a análise do medo em obras de Drummond e Kucinski. Via atlântica, São Paulo, n. 35, p. 137-154, jul. 2010.

CUNHA, C.; CINTRA, L. F. L. Nova gramática do português contemporâneo. 4. ed. Rio de Janeiro: Lexikon, 2007.

GUIMARÃES, I. C. T. G. A formação nominal em português: um estudo sintáticosemântico de bases enunciativas. Dissertação (Mestrado em Linguística Teórica e Descritiva) - Programa de Pós-graduação em Linguística, Universidade Federal de Minas Gerais, Belo Horizonte. 2011.

KENEDY, E. Possíveis contribuições da Linguística Gerativa à formação do professor de Língua Portuguesa. Rev. de Letras, on-line, v. 1, n. 32, p.72-79, jan./jun. 2013.

MIOTO, C.; SILVA, M. C. F.; LOPES, R. E. V. Novo manual de sintaxe. São Paulo: Contexto, 2013.

NEGRÃO, E. V. N.; SCHER, A. P.; VIOTTI, E. C. Sintaxe: explorando a estrutura da sentença. In: FIORIN, J.L. Introdução à linguística II: princípios de análise. São Paulo: Contexto, 2005. p.81-109.

NEVES, M. H. de M. Que gramática estudar na escola? Norma e uso na língua portuguesa. São Paulo: Contexto, 2004.

PILATI, E.; NAVES, R.; SALLES, H. (org.). Novos olhares para a gramática em sala de aula: questões para estudantes, professores e pesquisadores. São Paulo: Pontes, 2019.

PILATI, E. Linguística, gramática e aprendizagem ativa. Campinas, SP: Pontes, 2017. 
PINHO, A K. C. D. A.; COELHO, S. M. Uma reflexão sobre o papel das preposições na distinção entre complementos nominais de substantivos e adjuntos adnominais preposicionados. Filologia e linguística portuguesa, on-line, v. 21, n. 2, p. 191-209, 2019. Disponível em: https://doi.org/10.11606/issn.2176-9419.v21i2p191-209. Acesso em: 09 jan. 2021.

SEDRINS, A. P. Leitura. Estudos em sintaxe comparativa. On-line, n. 33, p. 17-29, jan./jun. 2004.

SEDRINS, A. P. Notas sobre extração no português brasileiro. Estudos linguísticos e literários. Salvador, n. 44, p. 101-120, jul.-dez. 2016.

SEDRINS, A. P. Restrições de extração de argumentos e adjuntos de nome no português brasileiro. Tese (Doutorado em Linguística) - Programa de Pós-graduação em Letras e Linguística, Universidade Federal de Alagoas. Maceió; 2009.

VIEIRA, S. R.; BRANDÃO, S. F. (Org.). Ensino de gramática: descrição e uso. São Paulo: Contexto, 2008. 